\title{
Intraportally delivered stem cell spheroids localize in the liver and protect hepatocytes against GalN/LPS-induced fulminant hepatic toxicity
}

\author{
Shobha Regmi ${ }^{1}$, Shiva Pathak', Tung Pham Thanh'1, Tiep Tien Nguyen ${ }^{1}$, Jong-Hyuk Sung ${ }^{2}$, Simmyung Yook ${ }^{3}$, \\ Jong Oh. Kim ${ }^{1}$, Chul Soon Yong ${ }^{1}$, Inho Choi ${ }^{4}$, Kyoung-Oh Doh ${ }^{5}$, Pil-Hoon Park', Jun-Beom Park ${ }^{6}$, Yoojin Seo ${ }^{7,8}$, \\ Bieong-Kil Kim ${ }^{5}$, Dong-Mok Lee ${ }^{9}$, Ik-Jae Moon $^{10}$, Hyung-Sik Kim ${ }^{7,8^{*}}$ and Jee-Heon Jeong ${ }^{1 *}$
}

\begin{abstract}
Background: Systemic inflammatory response syndrome (SIRS) is common in severe fulminant hepatic failure (FHF) and has a high mortality rate (20-50\%) due to irreversible cerebral edema or sepsis. Stem cell-based treatment has emerged as a promising alternative therapeutic strategy to prolong the survival of patients suffering from FHF via the inhibition of SIRS due to their immunomodulatory effects.

Methods: 3D spheroids of adipose-derived mesenchymal stem cells (3D-ADSC) were prepared by the hanging drop method. The efficacy of the 3D-ADSC to rescue FHF was evaluated in a D-galactosamine/lipopolysaccharide (GalN/LPS)-induced mouse model of FHF via intraportal transplantation of the spheroids.
\end{abstract}

Results: Intraportally delivered 3D-ADSC better engrafted and localized into the damaged livers compared to 2Dcultured adipose-derived mesenchymal stem cells (2D-ADSC). Transplantation of 3D-ADSC rescued 50\% of mice from FHF-induced lethality, whereas only $20 \%$ of mice survived when 2D-ADSC were transplanted. The improved transplantation outcomes correlated with the enhanced immunomodulatory effect of 3D-ADSC in the liver microenvironment.

Conclusion: The study shows that the transplantation of optimized 3D-ADSC can efficiently ameliorate GalN/LPSinduced FHF due to improved viability, resistance to exogenous ROS, and enhanced immunomodulatory effects of 3D-ADSC.

Keywords: Mesenchymal stem cell, 2D-cultured cells, Spheroids, Intraportal delivery, Fulminant hepatic failure

\section{Background}

Toxins, drugs, viral infections, and genetic and metabolic disorders cause liver dysfunction requiring medical intervention [1]. During fulminant hepatic failure (FHF; also known as acute liver failure (ALF)), bacterial toxins or other hepatotoxins cause massive hepatocellular damage $[2,3]$. In addition, systemic inflammatory response

\footnotetext{
* Correspondence: hskimcell@pusan.ac.kr; jeeheon@yu.ac.kr

7Department of Life Science in Dentistry, School of Dentistry, Pusan National University, Yangsan 50612, Republic of Korea

${ }^{1}$ College of Pharmacy, Yeungnam University, 280 Daehak-ro, Gyeongsan-si, Gyeongbuk-do 38541, Republic of Korea

Full list of author information is available at the end of the article
}

syndrome (SIRS) mediated by massive stimulation of innate and/or adaptive immune system is frequently observed in severe cases of FHF. In fact, SIRS is the leading cause of fatality in FHF and $20-50 \%$ of FHF patients succumb to irreversible cerebral edema or sepsis with multiple organ dysfunction [4]. Thus, suppression of excessive immune responses during liver dysfunction may reduce the risk of hepatic failure-induced mortality.

Liver transplantation is the only life-saving treatment for permanent liver failure; however, various obstacles, such as limited donor issue, risk of fungal infection during the procedures, immune rejection response against the graft, and long-term immunosuppressant-associated 
complications decrease the success rate $[5,6]$. To overcome the potential risks of whole organ transplantation, non-invasive cell-based therapy using primary hepatocytes is of keen interest for the treatment of liver diseases [7, 8]. However, many aspects of hepatocyte culture, including their isolation, expansion, and preservation, have proven to be difficult, and poor engraftment efficacy limits the hepatocyte transplantation $[9,10]$. In this context, mesenchymal stem cells (MSC) are promising candidates for cell therapy because of their multipotent differentiation ability and immunomodulatory activity [11-13]. Furthermore, MSC have been reported to rescue impaired hepatocytes by differentiating into hepatocyte-like cells and/or by improving the inflammatory, fibrotic microenvironment through paracrine effects [14] and preventing further liver damage during FHF [15]. Notably, earlier MSC-based therapies were mainly dependent on the multi-lineage differentiation ability, whereas recent studies have focused on the paracrine and autocrine functions of MSC-derived therapeutic factors [16-18]. Previous reports have revealed that the aggregation of MSC into 3D spheroids causes enhancement in the secretion of paracrine factors and proangiogenic cytokines $[19,20]$ and protection of the stemness [21, 22]. Furthermore, 3D culture methods have been reported to enhance stem cell survival in vitro as well as in vivo and provide better engraftment efficiency $[23,24]$. Thus, 3D culture methods offer a means of improving the efficacy of stem cell therapies and eliminate the need for genetic modification and growth factor delivery.

In cell therapy, the route of cell delivery must be considered deliberately to maximize therapeutic efficacy. In most cases, MSC are administrated via intravenous injection [25-27], which results in non-specific distributions of cells. The cells are primarily accumulated in the lungs, and only a small number of cells localize into the liver despite their homing ability [28]. Although various injection routes have been considered, including delivery into targeted areas, no report has been issued on maximizing the localization of the transplanted cells in models of liver injury. In the current study, we aimed to evaluate the therapeutic potential of adipose-derived mesenchymal stem cells (ADSC) in a D-galactosamine (GalN)/lipopolysaccharide (LPS)-induced murine model of hepatic injury, because it closely resembles FHF $[2,3]$. To enhance ADSC engraftment and localization in the liver, we delivered the $3 \mathrm{D}$ spheroids derived from ADSC (3D-ADSC) via the portal vein. The liver-entrapped 3D-ADSC helped in the modulation of inflammatory hepatic microenvironment through the secretion of anti-inflammatory cytokines/growth factors and improved outcomes of mesenchymal stem cell therapy in FHF.

\section{Material and methods \\ Cells}

Human adipose-derived mesenchymal stem cells (ADSC) were purchased from Zenbio (Morrisville, NC, USA). ADSC were cultured in alpha-MEM (Hyclone, South Logan, UT, USA) containing $10 \% v / v$ fetal bovine serum (Hyclone, South Logan, UT, USA) and 1\% v/v antibiotics/ antimycotics (GenDEPOT, Barker, TX, USA). Cells from passages $4-8$ were used in this study.

\section{Preparation and optimization of 3D-ADSC}

A previously described hanging drop technique was used to prepare 3D-ADSC [29]. The differently sized spheroids, i.e., $3 \mathrm{D}-\mathrm{ADSC}_{500}, 3 \mathrm{D}-\mathrm{ADSC}_{1000}$, 3D-ADSC $\mathrm{AD}_{200}$, and 3D$\mathrm{ADSC}_{4000}$ containing 500,1000, 2000, and 4000 ADSC per spheroid, respectively, were prepared. The viability and size of 3D-ADSC were considered for the optimization of size of the 3D-ADSC for in vivo studies. The viability of differently sized 3D-ADSC was assessed using a live/dead assay kit (Molecular Probes, Eugene, OR, USA), and Western blot analysis as reported previously [30].

\section{Induction of FHF}

Balb/c nude mice (7-8 weeks old) purchased from Orient Biosciences (Seoul, Republic of Korea) were used in this study. Animals were housed in the animal facility of Yeungnam University. Animal experimental protocols were approved by the regulations of Institutional Animal Care and Use Committee (IACUC) of Yeungnam University (IACUC: YL 2018-028). For the determination of the optimal dose required to induce FHF, mixtures of GalN (Carbosynth, Old Station Business Pk, Compton RG20 $6 \mathrm{NE}, \mathrm{UK})(1000,1500,2000$, or $3000 \mathrm{mg} / \mathrm{kg})$ and LPS (Sigma, St. Louis, MO, USA) $(20 \mu \mathrm{g} / \mathrm{kg})$ were administered intraperitoneally (i.p.). The anti-inflammatory effect of stem cells was evaluated using an optimized GalN/LPS dose (single injection; $1500 \mathrm{mg} / \mathrm{kg}$ GalN and $20 \mu \mathrm{g} / \mathrm{kg}$ LPS). Mice were divided randomly into different groups after the induction of ALF.

\section{Intraportal delivery of ADSC}

The therapeutic efficacy of ADSC was determined by infusing cells via the portal vein $5 \mathrm{~h}$ after GalN/LPS injection. One thousand $3 \mathrm{D}-\mathrm{ADSC}_{1000}$ or $1 \times 10^{6} 2 \mathrm{D}$-ADSC were suspended in $100 \mu \mathrm{L}$ PBS and injected into the portal vein using an insulin syringe. Sham group received an intraportal injection of $100 \mu \mathrm{L}$ PBS. Subsequently, mice were monitored 6 hourly and blood samples were obtained at 1, 3, 5, and 7 days after transplantation. Serum glutamate-pyruvate transaminase (GPT) and serum glutamic oxaloacetic transaminase (GOT) levels were measured via the colorimetric method using a chemistry 
analyzer (DRI-CHEM 4000i, FUJIFILM Corporation, Tokyo, Japan).

\section{DNA extraction and real-time PCR}

At $10 \mathrm{~h}$ after MSC transplantation, the livers, lungs, and hearts were isolated to investigate the presence of the transplanted cells in these organs. Depending on the weight of the organ, lysis buffer was added and homogenized. Afterwards, DNA was extracted using a genomic DNA extraction kit (Bioneer Corp, Daejeon, South Korea) and quantified using a spectrophotometer (Nanodrop; TECAN). Real-time PCR (RT-PCR) was performed using $25 \mathrm{ng}$ DNA, $5 \mu \mathrm{L}$ SYBER green (Thermo Scientific, Waltham, MA, USA), $37.5 \mathrm{nM}$ ALU primer, and $450 \mathrm{nM}$ GAPDH primer. The primer sequences used were as follows: ALU, 5'-GTCAGGAGATCGAGACCATCCC-3' (F) and 5'-TCCTGCCTCAGCCTCCCAAG-3' (R), and GAPDH, 5'-ACCACAGTCCATGCCATCAC-3' (F) and 5' -TCCACCACCCTGTTGCTGTA-3' (R). Calibration curve was prepared using crossing point $(\mathrm{Cp})$ values obtained with various amounts of human DNA $(16 \%, 8 \%$, $4 \%, 2 \%, 1 \%, 0.5 \%, 0.25 \%, 0.125 \%, 0.0625 \%, 0.03125 \%$, $0.0156 \%, 0.0078 \%$, and $0.0039 \%$ ).

\section{Levels of ROS and ROS-related enzymes in $3 \mathrm{D}-$ ADSC $_{1000}$}

To understand the mechanism responsible for the effects of $3 \mathrm{D}-\mathrm{ADSC}_{1000}$ transplantation, amounts of ROS produced by $2 \mathrm{D}-\mathrm{ADSC}$ and $3 \mathrm{D}-\mathrm{ADSC}_{1000}$ were evaluated by the fluorescence method using $20 \mu \mathrm{M}$ of $2^{\prime}, 7^{\prime}$ dichlorofluorescein diacetate (DCFDA) (Sigma-Aldrich, St. Louis, MO, USA) and normalized with the DNA contents measured using PicoGreen Kit (Molecular Probes, Eugene, OR, USA). Similarly, levels of the antioxidant enzymes superoxide dismutase 2 (SOD2), catalase (CAT), and hemeoxygenase-1 (HO-1) were determined by the Western blot analysis using antibodies against SOD2 (Cell Signaling Technology, Danvers, MA, USA), CAT (Cell Signaling), and HO-1 (Cell Signaling).

Viability of 3D-ADSC 1000 under oxidative stress condition In order to examine cell viability in a highly oxidative environment that resembles the FHF liver, $3 \times 10^{4}$ monolayer-cultured MSCs or 30 spheroids (each spheroid containing 1000 MSCs) were cultured with different concentrations of TBHP (tert-butyl hydroperoxide) (Tokyo Chemical Industry, Nihonbashi-honcho, Chuo-ku, Tokyo, Japan) (200 and $400 \mu \mathrm{M})$ for $24 \mathrm{~h}$ in a 96 -well plate. Viability was assayed by using live/dead imaging and Cell Counting Kit-8 (CCK-8) as described previously [30].

\section{Anti-inflammatory effects of 3D-ADSC 1000 and 2D-ADSC}

The levels of prostaglandin E2 $\left(\mathrm{PGE}_{2}\right)$ secreted in supernatants after 3 days of culture of 2D-ADSC and 3D$\mathrm{ADSC}_{1000}$ were measured using a PGE 2 ELISA kit ( $\mathrm{R} \& \mathrm{D}$
Systems, Minneapolis, MN, USA). Similarly, in vitro antiinflammatory effects of 3D-ADSC 1000 and 2D-ADSC were assessed by culturing them with activated macrophages. Briefly, RAW 264.7 macrophages were cultured at a density of $4 \times 10^{4}$ per well in a 96-well plate for $24 \mathrm{~h}$ and activated by adding $1 \mathrm{mg} / \mathrm{mL}$ of LPS for $90 \mathrm{~min}$. Ten 3D$\mathrm{ADSC}_{1000}$ or $1 \times 10^{4} 2 \mathrm{D}$-ADSC were added to each well, and $10 \mathrm{~h}$ later, supernatants were collected, centrifuged, and stored at $-70{ }^{\circ} \mathrm{C}$ until analysis. Levels of IL-10 and TNF- $\alpha$ were measured by ELISA using a Mouse IL-10 ELISA kit (R \& D Systems, Minneapolis, MN, USA) or a Mouse TNF- $\alpha$ kit (Elabscience, Bethesda, MD, USA), respectively. Finally, levels of ROS in activated macrophages were measured by the fluorescence method using DCFDA.

\section{In vivo assessment of the anti-inflammatory effect of 3D-} ADSC $_{1000}$ and 2D-ADSC

For the in vivo assessment of the effect of $3 \mathrm{D}-\mathrm{ADSC}_{1000}$ and 2D-ADSC in attenuating inflammation in the FHF model, polarization of macrophage in the liver was evaluated using flow cytometry. After $7 \mathrm{~h}$ of cell transplantation, isolation of monocytes from the liver was conducted as described previously [31]. The isolated cells were stained with anti-mouse PE-Cy7-conjugated CD11b (Biolegend, San Diego, CA, USA), PE-conjugated F4/80 (Biolegend), APC-Cy7-conjugated CD86 (Biolegend), and PE-Cy7-conjugated CD206 (Biolegend) and analyzed by BD FACS Verse flow cytometer (BD Biosciences, San Jose, CA, USA). To check M1 and M2 phenotypes of macrophage, $\mathrm{F} 4 / 80^{+}$population was selected, and the expression of CD86 (M1 surface marker) and CD206 (M2 surface marker) was evaluated. Median fluorescence intensity (MFI) was calculated using FlowJo Software (FlowJo LLC, OR, USA). In addition, the concentration of IL-10 in serum was also evaluated by ELISA.

\section{Histochemical analysis}

$3 \mathrm{D}-\mathrm{ADSC}_{1000^{-}}$and 2D-ADSC-injected mice were sacrificed $7 \mathrm{~h}$ after injections, and the livers were surgically removed, fixed in $4 \%$ paraformaldehyde solution, and embedded in paraffin. Samples were then sectioned at $5 \mu \mathrm{m}$, deparaffinized in xylene, rehydrated using an alcohol series, and stained with hematoxylin and eosin (H\&E).

\section{Ex vivo imaging}

Cells were stained with VivoTrack680 (pernElmer, Boston, MA, USA) according to the manufacturer's protocol. Then, $1 \times 10^{6}$ monolayer cells or $10003 \mathrm{D}^{-A_{D S C}} 1000$ were injected into the portal vein via a surgical process. At $7 \mathrm{~h}$ post-transplantation, different organs were isolated to observe the fluorescence using in vivo imaging system (FOBI; NeoScience, Suwon, Korea). 


\section{Statistical analysis}

Results are expressed as mean \pm SEM. Data were analyzed using GraphPad Prism software version 5 (GraphPad Software, La Jolla, CA, USA). Unless otherwise stated, unpaired $t$ test was performed to calculate the statistical significance values. Statistical significance was accepted for $p<0.05$.

\section{Results}

\section{Optimization of 3D-ADSC}

To optimize the size of spheroids, we prepared 3D-ADSC of different sizes and compared cell viability with 2DADSC. The average diameters of 3D-ADSC 500 , 3D$\mathrm{ADSC}_{1000}, 3 \mathrm{D}-\mathrm{ADSC}_{2000}$, and $3 \mathrm{D}-\mathrm{ADSC}_{4000}$ were $91.97 \pm$ $11.80, \quad 125.00 \pm 15.93, \quad 161.70 \pm 24.39, \quad$ and $203.86 \pm$ $25.05 \mu \mathrm{m}$, respectively (Fig. 1a-c). Interestingly, Western blot analysis revealed two- to threefold increase in expressions of Bcl-2 (anti-apoptotic) and two- to threefold decrease in expressions of Bax (pro-apoptotic) in 3D-ADSC with different cell numbers when compared to the 2DADSC. Among the 3D-ADSC groups containing different numbers of cells, $3 \mathrm{D}-\mathrm{ADSC}_{1000}$ was chosen for further experiments because this group exhibited higher cell viability and anti-apoptotic property compared to the other spheroid groups (Fig. 1d, e). In addition, given that spheroids with size exceeding $150 \mu \mathrm{m}$ suffer from hypoxia-induced cell death after transplantation [32], 3D-ADSC 1000 with size $\sim 125 \mu \mathrm{m}$ was expected to have improved efficacy, as well as minimum risk of thrombosis and embolism after transplantation.

\section{Intraportal delivery of 3D-ADSC 1000 ameliorated FHF}

Dosage of GalN and LPS was optimized, and 1500 $\mathrm{mg} / \mathrm{kg}$ GalN and $20 \mu \mathrm{g} / \mathrm{kg}$ LPS were chosen for the induction of FHF in BALB/c nude mice, which resulted in the deaths of 2 out of 3 mice $24 \mathrm{~h}$ after administration (Additional file 1: Figure S1). To assess the efficacy of ADSC in FHF, $1 \times 10^{6} 2 \mathrm{D}$-ADSC or $10003 \mathrm{D}-\mathrm{ADSC}_{1000}$ were delivered via the portal vein. Figure 2a shows the timeline of the study. Transplantation of $3 \mathrm{D}-\mathrm{ADSC}_{1000}$ significantly improved the survival of mice (survival rate 50\%) compared with the sham-operated group (18\%) and the 2D-ADSCtreated group (survival rate 20\%) (Fig. 2b).

Serum levels of GOT and GPT in the sham, 2D-ADSC, and $3 \mathrm{D}-\mathrm{ADSC}_{1000}$ groups $5 \mathrm{~h}$ after GaLN/LPS injection, were significantly higher than those of untreated mice (untreated mice; GOT $110 \pm 20$ and GPT $32 \pm 9$ ) (Additional file 1: Figure S2). Notably, no significant difference was observed in GPT and GOT levels among all the experimental groups at the time of transplantation. However, at $19 \mathrm{~h}$ after cell administration, the levels of serum GPT and GOT were markedly lower in the $3 \mathrm{D}-\mathrm{ADSC}_{1000}$-treated group compared to the 2D-ADSC-treated group (GPT: $p<$
0.01, GOT: $p<0.001)$ or the sham group (GPT: $p<0.001$, GOT: $p<0.01$ ), indicating a reduction in the severity of liver injury after spheroid transplantation. Similarly, at day 3 post-transplantation, serum GPT levels in the 3DADSC $_{1000}$ group were significantly lower compared to those in the 2D-ADSC $(p<0.01)$ and sham $(p<0.05)$ groups (Fig. 2c, d).

Histological analysis of liver sections from the sham and 2D-ADSC-treated groups revealed an accumulation of erythrocytes in the extra-sinusoidal region, signifying the damage of hepatic parenchymal and sinusoidal endothelial cells. In addition, the high extent of thrombosis was observed in the liver of 2D-ADSC-transplanted mice. In contrast, minimal thrombosis was observed in the recipients with $3 \mathrm{D}-\mathrm{ADSC}_{1000}$ (Fig. 3a). Gross observation at $7 \mathrm{~h}$ after cell delivery demonstrated the formation of a substantial infarcted region in the liver of the 2D-ADSC group, but no significant infarction was observed in the $3 \mathrm{D}-\mathrm{ADSC}_{1000}$ group (Additional file 1: Figure S3).

\section{Intraportally transplanted 3D-ADMSC ${ }_{1000}$ localized in the liver}

Histological analysis revealed the localization of transplanted $3 \mathrm{D}-\mathrm{ADSC}_{1000}$ in the portal triad. In addition, $\mathrm{H} \& \mathrm{E}$ staining showed an intact morphology of $3 \mathrm{D}-\mathrm{ADSC}_{1000}$ at 7 $\mathrm{h}$ of transplantation (Fig. 3a). Similarly, ex vivo imaging of the liver and lungs also demonstrated the localization of ADSC in the liver and minimal migration into the lungs in the $3 \mathrm{D}-\mathrm{ADSC}_{1000}$-transplanted group (Fig. 3b). Further, to quantify total human ADSC after transplantation, the expression of human-specific ALU sequence was evaluated in the liver, lungs, and heart. A calibration curve was generated using different percentages of human DNA mixed with mouse DNA (Fig. 3c). This equation was further used to calculate the total percent of human DNA in mouse tissue. Results revealed a higher number of cells distributed in the liver of the 3D-ADSC 1000 -transplanted group compared to the 2D-ADSC-transplanted group. In contrast, the percentage of human DNA in the lungs of the $3 \mathrm{D}-\mathrm{ADSC}_{1000^{-}}$ transplanted group was significantly lower than that of the 2D-ADSC-transplanted group, suggesting a minimal migration of ADSC from the spheroids to extrahepatic tissues after transplantation. No significant migration of MSC was observed in the heart of both groups (Fig. 3b, d).

\section{D-ADSC 1000 were resistant to oxidative stress}

To evaluate the effect of oxidative stress on the viability of 2D-ADSC and the spheroids in vitro, 2D-ADSC and 3D$\mathrm{ADSC}_{1000}$ were treated with TBHP. Results unveiled a higher number of cells stained with ethidium homodimer1 in TBHP-treated 2D-ADSC (Fig. 4a) and $<20 \%$ of cells were viable at both concentrations (Fig. 4b). In contrast, cell viability in the $3 \mathrm{D}-\mathrm{ADSC}_{1000}$ was not diminished by TBHP at $200 \mu \mathrm{M}$ and approximately $40 \%$ of the cells 


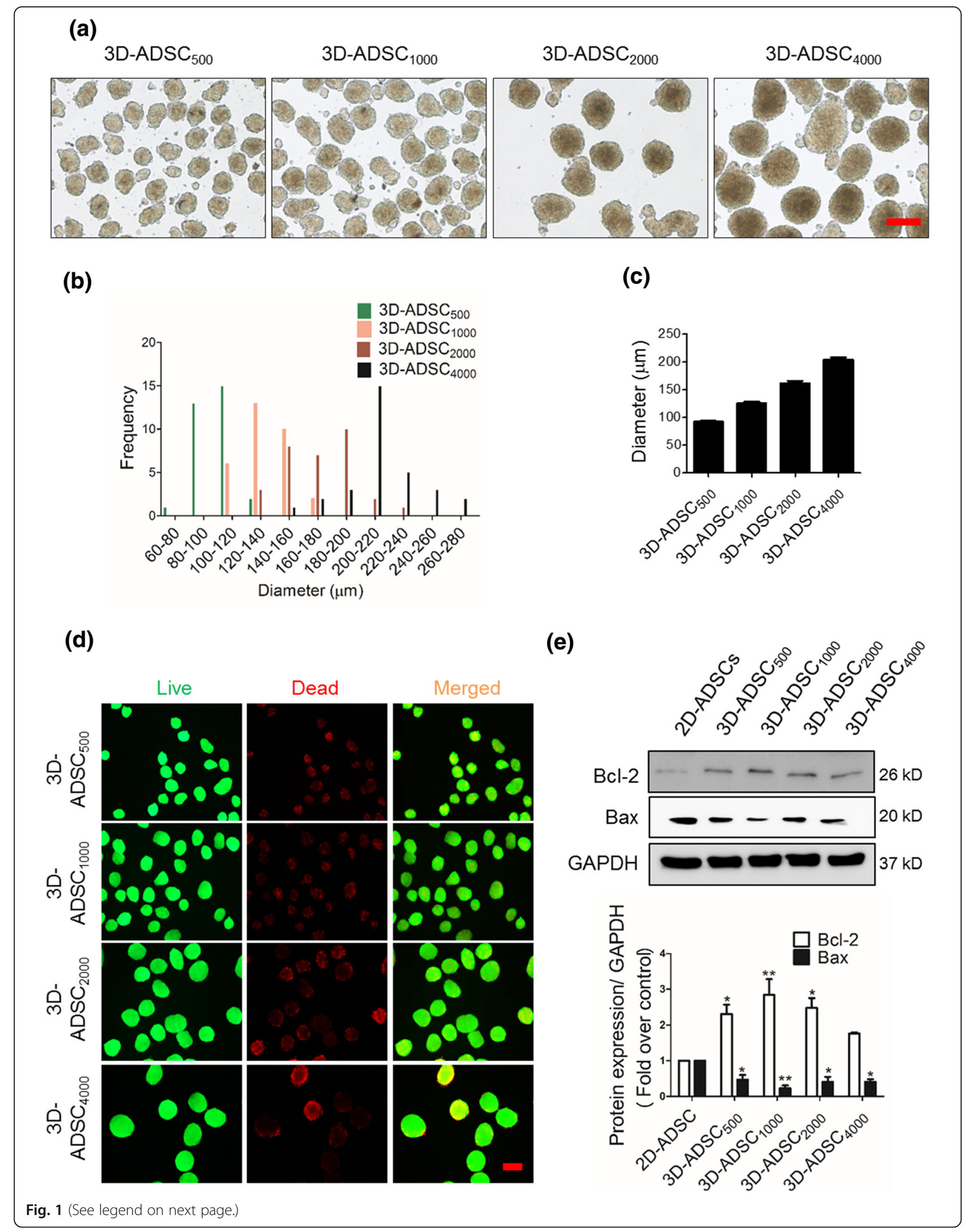


(See figure on previous page.)

Fig. 1 Formation of 3D spheroids of different sizes. a Morphology of 3D-ADSC, magnification: $\times 100$, scale bar: $200 \mu$ m. b Size distribution. c Size of 3D-ADSC $(n=31)$ where values represent mean \pm SEM. $\mathbf{d}$ Live/dead images for the determination of viability of differently-sized 3D-ADSC, magnification: $\times 100$, scale bar: $200 \mu \mathrm{m}$. e Representative blot showing cell viability of 2D-ADSC and differently-sized 3D-ADSC and quantitative expressions of proteins measured using GelQuantNET software. The values represent mean \pm SEM of three independent experiments. 3D-ADSC 500, 500 ADSC per spheroid; 3D-ADSC 1000,1000 ADSC per spheroid; 3D-ADSC 2000,2000 ADSC per spheroid; 3D-ADSC 4000,4000 ADSC per spheroid. ${ }^{*} p<0.05$ and ${ }^{* *} p<0.01$

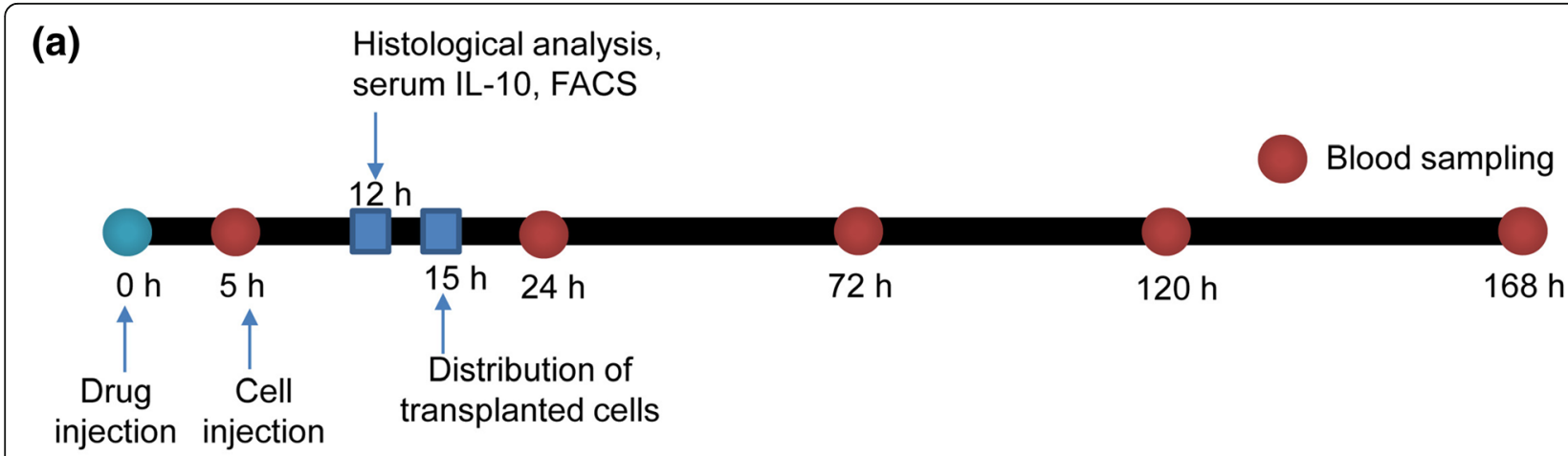

(b)

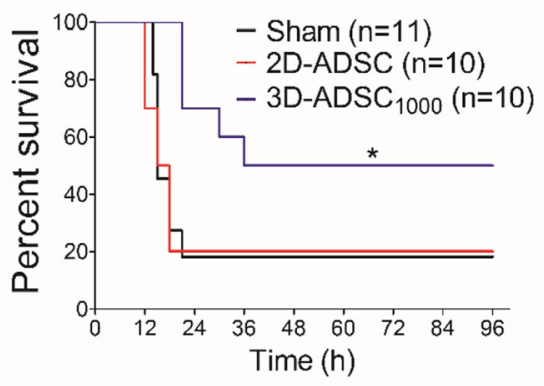

(c)

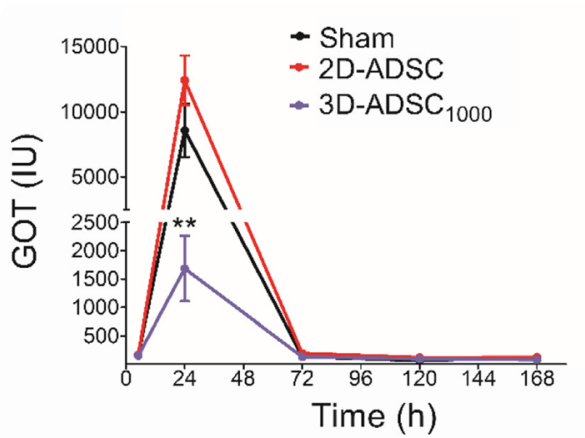

(d)

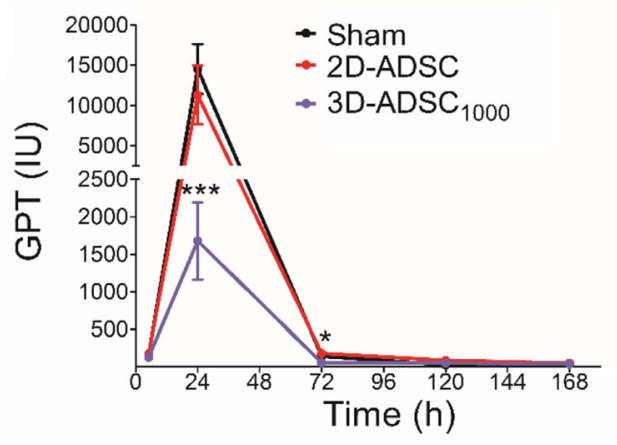

Fig. 2 3D-ADSC 1000 rescued mice from GalN/LPS-induced lethal FHF. a Timeline of the study. b Survival curve of $1500 \mathrm{mg} / \mathrm{kg}$ GalN and $20 \mu \mathrm{m} / \mathrm{kg}$ LPS-treated BALB/C nude mice injected with PBS, $1 \times 10^{6}$ 2D-ADSC, or 1000 3D-ADSC 1000 . Log-rank (Mantel-Cox) test was used to calculate the statistical significance. c Serum glutamic oxaloacetic transaminase (GOT) levels. d Serum glutamic pyruvic transaminase (GPT) levels. GPT and GOT were analyzed in the surviving mice via the colorimetric method using a chemistry analyzer. Data represent mean \pm SEM. ${ }^{*} p<0.05,{ }^{* *} p<0.01$, and ${ }^{* * *} p<0.001$ 
(a)

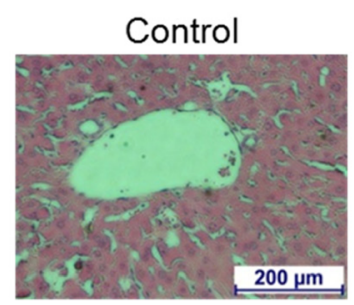

2D-ADSC

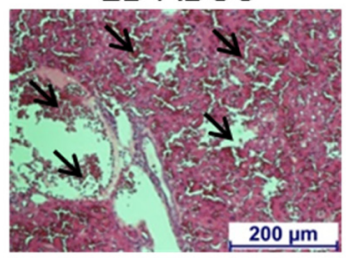

(b)

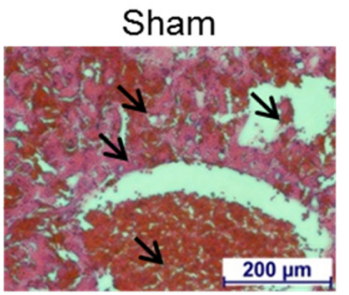

$3 \mathrm{D}-\mathrm{ADSC}_{1000}$

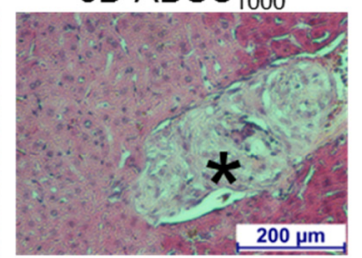

(c)

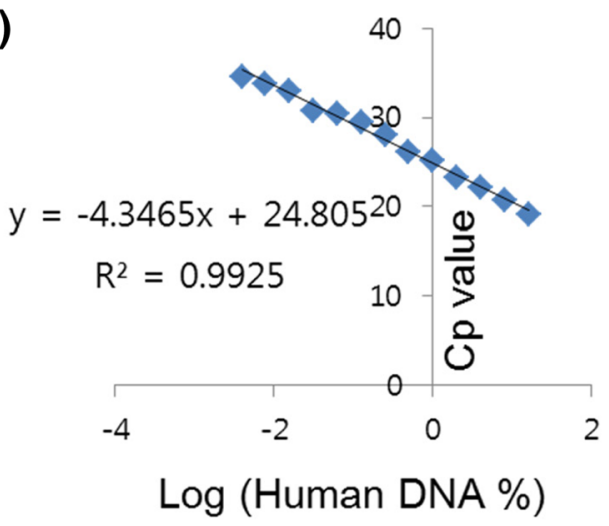

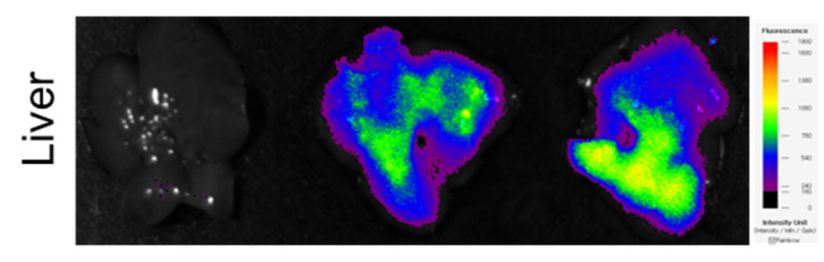

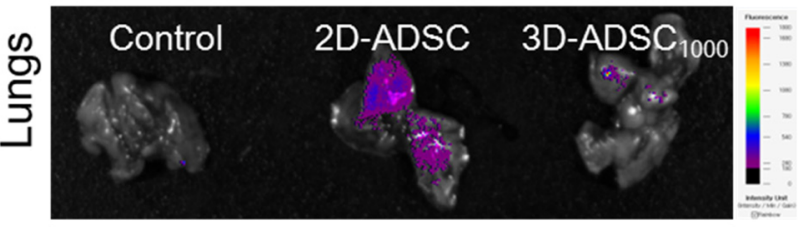

(d)

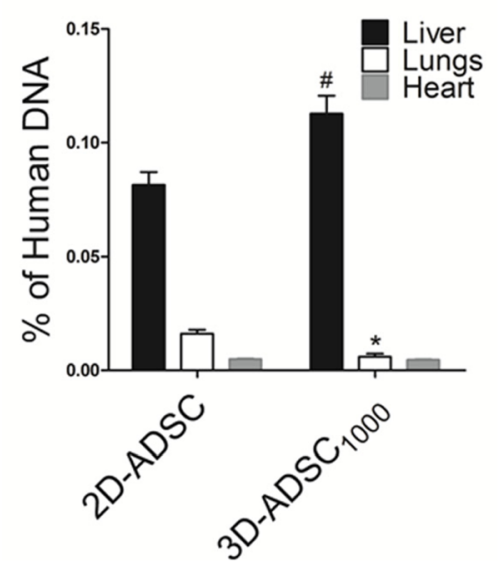

Fig. 3 Fate of 2D- and 3D-cultured MSCs after transplantation via portal vein. a Histology of the liver $12 \mathrm{~h}$ after GalN/LPS administration; magnification: $\times 100$, scale bar: $200 \mu \mathrm{m}$. Arrows indicate thrombosis, and the asterisk indicates localization of 3D-ADSC 1000 in the liver. $\mathbf{b}$ Ex vivo imaging to observe the extrahepatic distribution of the transplanted cells after intraportal delivery. At $7 \mathrm{~h}$ of intraportal delivery of MSCs, ex vivo imaging was performed. Fluorescence was observed in the lungs of the 2D-ADSC-delivered group. However, negligible fluorescence was observed in the lungs of the 3D-ADSC 1000 -delivered group. In addition, significantly higher fluorescence intensity was observed in the liver of the 3D-ADSC 1000 -transplanted group compared to the 2D-ADSC-transplanted group. c Calibration curve for the determination of human DNA. $\mathbf{d}$ Percentage of human DNA observed in vital organs at $10 \mathrm{~h}$ of MSC transplantation $(n=3)$. The values represent mean \pm SEM. * $p<0.05$ vs $2 \mathrm{D}$ ADSC in the lungs and ${ }^{\#} p<0.05$ vs 2D-ADSC in the liver

remained viable when they were treated with TBHP at $400 \mu \mathrm{M}$ (Fig. 4c, d). To investigate the mechanism underlying the enhanced resistance of $3 \mathrm{D}-\mathrm{ADSC}_{1000}$ against oxidative stress, we measured levels of ROS, HO-1, SOD2, and CAT in $2 \mathrm{D}-\mathrm{ADSC}$ and $3 \mathrm{D}-\mathrm{ADSC}_{1000}$. Interestingly, we found a significantly lower ( 50\% lower) level of ROS in $3 \mathrm{D}-\mathrm{ADSC}_{1000}$ compared to 2D-ADSC (Fig. 4e). Similarly, the expression of antioxidant proteins including HO-1, CAT, and SOD2 were remarkably higher in 3D$\mathrm{ADSC}_{1000}$ compared to those of 2D-ADSC (Fig. 4f-h). These findings suggest that $3 \mathrm{D}-\mathrm{ADSC}_{1000}$ possess improved resistant mechanism against oxidative stress through the upregulation of anti-oxidative enzymes.

\section{D-ADSC 1000 transplantation exerted improved} immunomodulation

The GalN/LPS-induced FHF model is known to be accompanied by the activation of Kupffer cells and monocytes, which lead to inflammatory reactions in the liver, hepatocyte death, and systemic inflammation [33]. As $\mathrm{PGE}_{2}$ has been reported to play a vital role in the immunosuppressive effect of mesenchymal stem cells on monocytes, we quantified amounts of $\mathrm{PGE}_{2}$ secreted by $2 \mathrm{D}$-ADSC and $3 \mathrm{D}-\mathrm{ADSC}_{1000}$. Interestingly, we found a dramatically higher level of $\mathrm{PGE}_{2}$ secreted by $3 \mathrm{D}$ ADSC $_{1000}(\sim 90$-fold $)$ compared to that of 2D-ADSC (Fig. 5a). Furthermore, $\mathrm{COX}_{2}$, which regulates $\mathrm{PGE}_{2}$ 
(a)

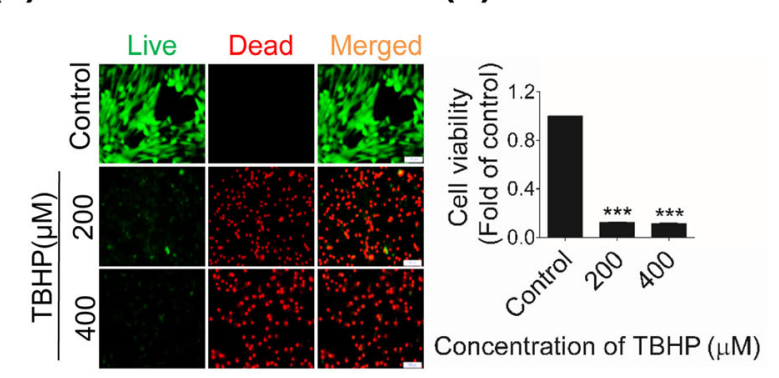

(e)

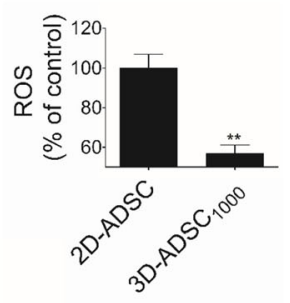

(f)

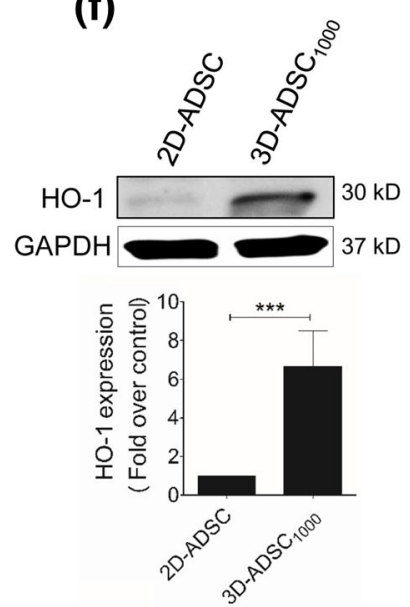

(c)

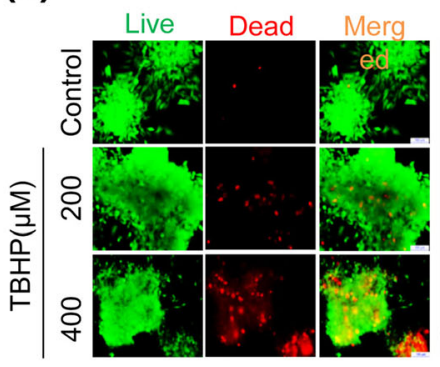

(g)
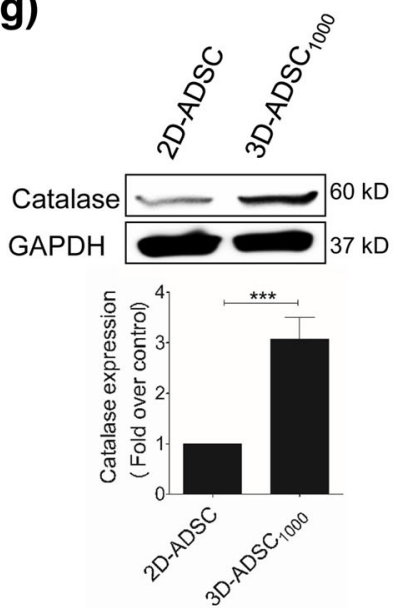

(d)

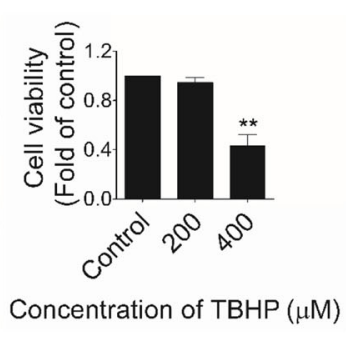

(h)

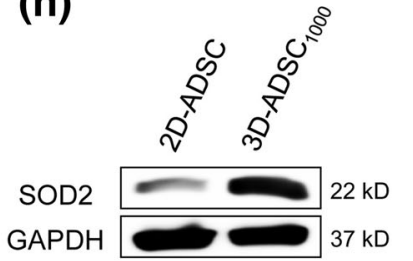

Fig. 4 3D-ADSC 1000 resisted to oxidative stress in vitro. a Qualitative analysis of the viability of 2D-ADSC $24 \mathrm{~h}$ after treatment with exogenous oxidant (TBHP) using live/dead imaging; magnification $\times 100$, scale bar $100 \mu \mathrm{m}$. b Quantitative analysis of viability of 2D-ADSC $24 \mathrm{~h}$ after treatment with exogenous oxidant (TBHP) using CCK-8 assay. Data represent the mean \pm SEM of three independent experiments. c Representative live/dead image showing the viability of 3D-ADSC $100024 \mathrm{~h}$ after treatment with TBHP; magnification $\times 100$, scale bar $100 \mu$ m. $\mathbf{d}$ Quantitative assessment of viability of 3D-ADSC $100024 \mathrm{~h}$ after treatment with TBHP using CCK-8 assay. The graph represents mean \pm SEM of three independent experiments. e Basal levels of ROS in 2D-ADSC and 3D-ADSC 1000 determined by using DCFDA reagent (mean \pm SEM, three independent experiments). $\mathbf{f}$ Representative blot for basal level expressions of HO-1 in 3D-ADSC and 2D-ADSC and quantitative evaluation of the HO-1 expression from three independent experiments using GelQuantNET software. Representative blots and quantitative expressions of the antioxidant enzymes $\mathbf{g}$ SOD2 and $\mathbf{h}$ catalase (mean \pm SEM, three independent experiments). ${ }^{* *} p<0.01$ and ${ }^{* * *} p<0.001$

secretion, was markedly upregulated in $3 \mathrm{D}-\mathrm{ADSC}_{1000}$ as compared with 2D-ADSC (Fig. 5b). Interestingly, when

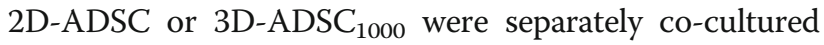
with the activated macrophages, ROS production in the macrophages co-cultured with $3 \mathrm{D}-\mathrm{ADSC}_{1000}$ was remarkably attenuated as compared to that in the macrophages co-cultured with 2D-ADSC $(p<0.05)$ (Fig. 5c). In addition, production of IL-10 was significantly elevated when the macrophages were co-cultured with the 2DADSC or $3 \mathrm{D}-\mathrm{ADSC} \mathrm{C}_{1000}$ compared to the LPS-stimulated macrophages $(p<0.0001)$. Notably, IL-10 secretion was greater in the macrophages co-cultured with 3D$\mathrm{ADSC}_{1000}$ than in the macrophages co-cultured with 2DADSC (Fig. $5 d$ ). In contrast, TNF- $\alpha$ secretion was reduced when the activated macrophages were co-cultured with $2 \mathrm{D}-\mathrm{ADSC}$ or $3 \mathrm{D}-\mathrm{ADSC}_{1000}$, but this inhibitory effect was significantly higher when the macrophages were co-cultured with $3 \mathrm{D}-\mathrm{ADSC}_{1000}(p<0.01$ vs $2 \mathrm{D}-\mathrm{ADSC})$ (Fig. 5e).
We next investigated whether 3D-ADSC 1000 could exert immunoregulatory efficacy in vivo. The evaluation of macrophage infiltration and polarization in the liver showed an enhanced immunomodulatory effect of 3D$\mathrm{ADSC}_{1000}$ to attenuate the liver inflammation. Macrophage population $\left(\mathrm{CD} 11 \mathrm{~b}^{+} \mathrm{F} 4 / 80^{+}\right)$was significantly upregulated in sham $(p<0.001), 2 \mathrm{D}-\mathrm{ADSC}(p<0.001)$, and $3 \mathrm{D}-\mathrm{ADSC}_{1000}(p<0.05)$ compared to control mice However, in the $3 \mathrm{D}-\mathrm{ADSC}_{1000}$-transplanted group, a significant reduction in the macrophage population was observed compared to the sham $(p<0.001)$ or 2D-ADSC groups $(p<0.05)$ (Fig. 6a). Moreover, there was a significant reduction in the expression of M1 surface marker (CD86) (Fig. 6b,c), and an upregulation of M2 surface marker (CD206) (Fig. 6d,e) among the $\mathrm{F} 4 / 80^{+}$macrophages of the $3 \mathrm{D}$-ADSC ${ }_{1000}$-transplanted group compared to the 2D-ADSC $(p<0.05)$ or sham group $(p<$ $0.001)$, implying the polarization of macrophage into M2 
(a)

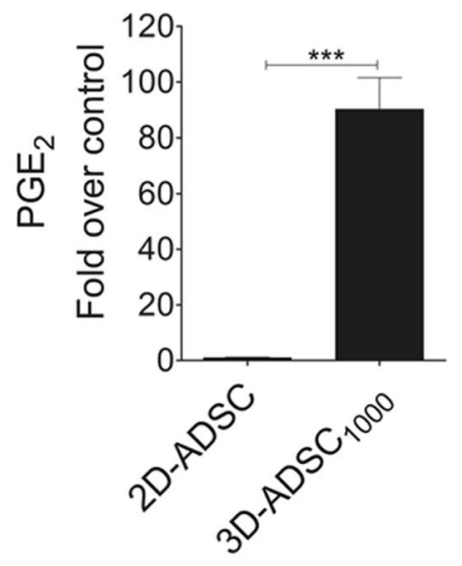

(b)

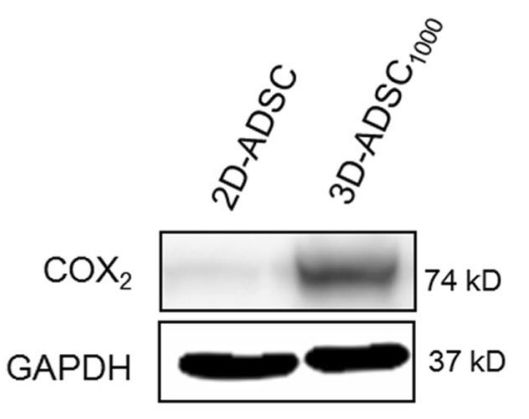

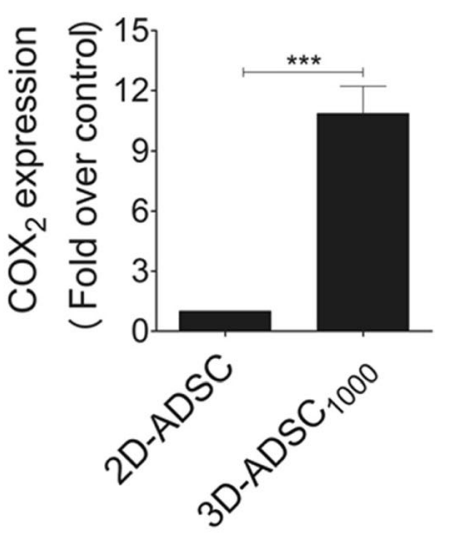

(c)

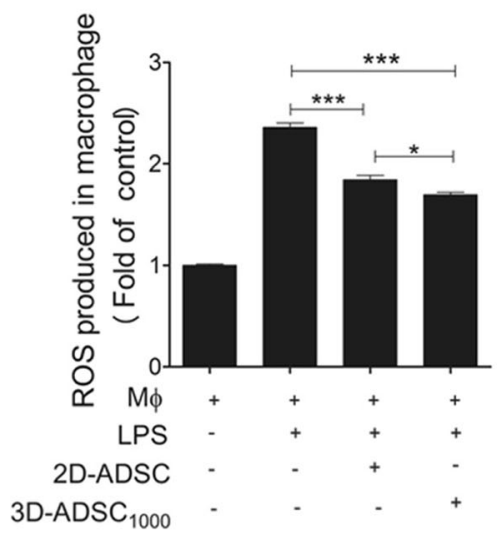

(d)

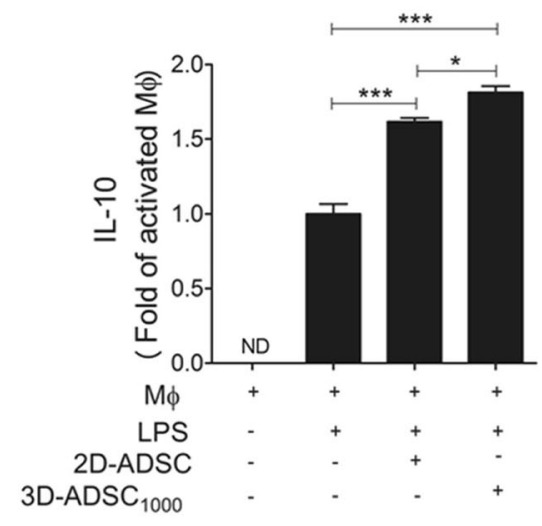

(e)

Fig. 5 3D-ADSC 1000 exerted enhanced immunomodulatory activity. a Basal levels of PGE secreted by 2D-ADSC and 3D-ADSC 1000 . Data represent mean \pm SEM of three independent experiments. $\mathbf{b}$ Representative blot of COX 2 expression in 2D-ADSC and 3D-ADSC 1000 and quantitative estimation of $\mathrm{COX}_{2}$ expression using GelQuantNET software. Data represent mean \pm SEM from three independent experiments. $\mathbf{c}$ Evaluation of ROS production in LPS-activated macrophages after co-culture with 2D-ADSC or 3D-ADSC 1000 using fluorescence method. The graph represents mean \pm SEM from three independent experiments (one-way ANOVA). $\mathbf{d} I \mathrm{~L}-10$ (anti-inflammatory) secretions after co-culturing activated macrophages with 2D-ADSC or 3D-ADSC 1000 for $10 \mathrm{~h}$ using ELISA. Data indicate mean \pm SEM from three independent experiments (one-way ANOVA). e TNF-a secretion after co-culture of activated macrophage with 2D-ADSC or 3D-ADSC 1000 for $10 \mathrm{~h}$. Data indicate mean \pm SEM from three independent experiments. ${ }^{*} p<0.05,{ }^{* *} p<0.01$, and ${ }^{* * *} p<0.001$

phenotype after injection of $3 \mathrm{D}-\mathrm{ADSC}_{1000}$. Furthermore, an increase in serum IL-10 level in the $3 \mathrm{D}-\mathrm{ADSC}_{1000^{-}}$ transplanted group supported the upregulation of $\mathrm{M} 2$ macrophage (Fig. 6f). These results suggest that ADSC spheroids can robustly polarize the macrophages from M1 (inflammatory) to M2 (anti-inflammatory) phenotype, presumably via elevated $\mathrm{PGE}_{2}$ production (Fig. 7).

\section{Discussion}

Stem cell therapy is based on cell replacement by differentiation into desired cell types or on rearrangement of the microenvironment in a manner that promotes tissue repair [34]. MSC have been reported to be useful in FHF due to their ability to differentiate into hepatocytes [35]. Furthermore, MSC have the ability to improve the liver microenvironment and promote the regeneration of hepatocytes by regulating inflammatory cells and cytokines $[14,36]$. Although MSC have been demonstrated to be beneficial in various disease conditions, their effectiveness is compromised by limited survival and engraftment after transplantation [37]. 3D-ADSC have been reported to enhance cell viability possibly due to the phosphorylation of AKT or the upregulations of hypoxia-induced survival factors and nutrient deprivation-induced factors [23, 38-40]. Recently, we have developed extracellular matrix-modified scaffolds to enhance viability and therapeutic effectiveness in inflammatory diseases [41]. In the current study, transplantation of viability-strengthened MSC spheroids via the portal vein alleviated ALF by exerting a local immunomodulatory function. 


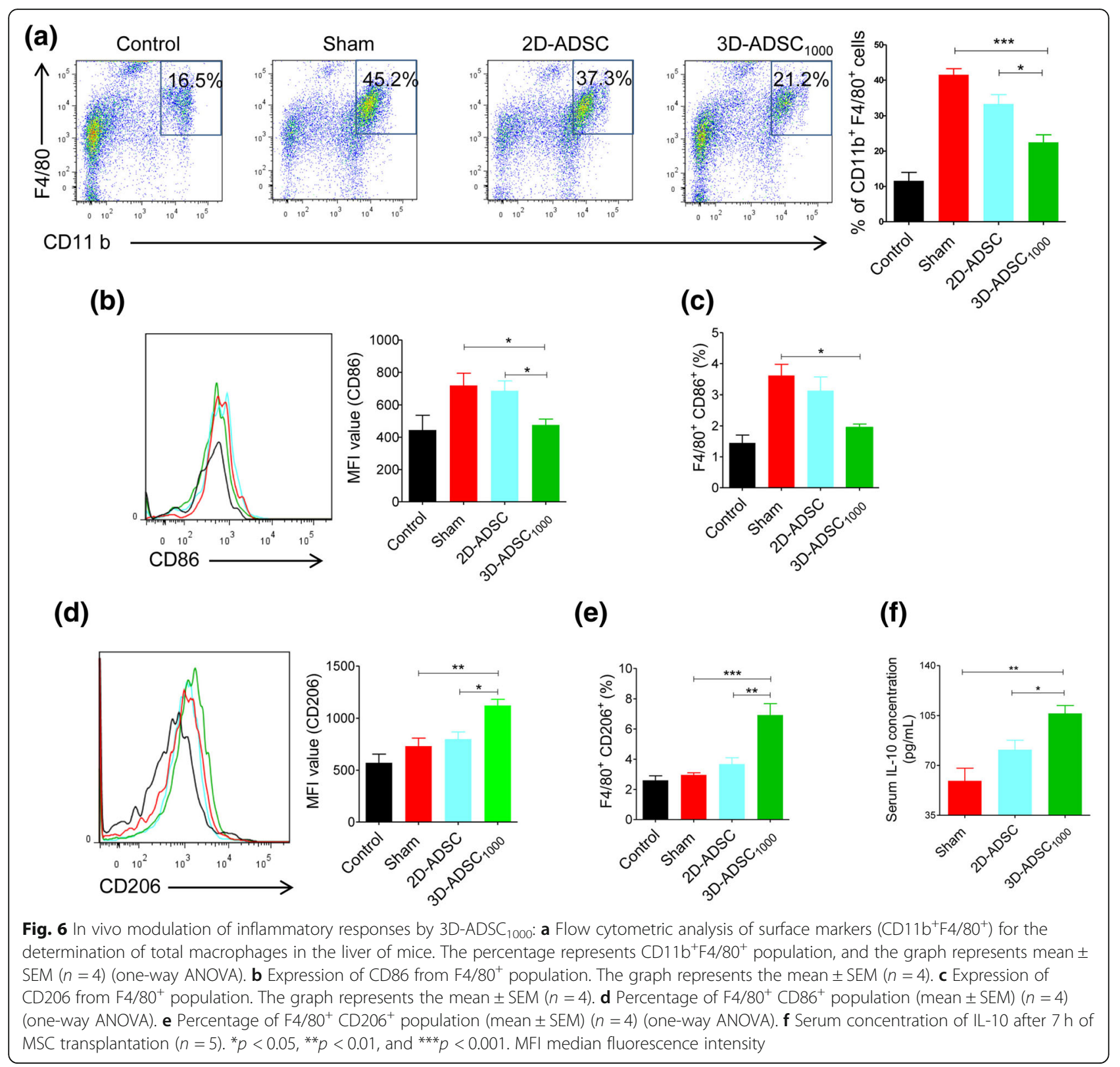

Delivery of cells via the portal vein might increase risks of venous thrombosis and embolism. In a recent study, thrombosis and infarction were more prominent after intraportal delivery of 2D-ADSC compared to the 3DADSC-delivered group [42], which may be due to higher expressions of thrombogenic proteins, including tissue factor (TF) and chemokine (C-C motif) ligand 2 (CCL2) in 2D-ADSC compared to that of the 3D-ADSC. Furthermore, 3D-ADSC containing 10,000 cells were reported to aggravate thrombosis and infarction in the livers [42], which indicates a necessity of control over spheroid size to protect the cells against hypoxia or nutrient deficiency after transplantation. The size-controlled MSC spheroids used for in vivo experiments in the current study survived well in a highly oxidative environment under in vitro conditions. This resembles the environment of an inflamed liver during FHF. Interestingly, no signs of hepatic thrombosis were observed in the 3D-ADSC-transplanted group.

GalN/LPS-induced FHF induces the activation of liver macrophage and the recruitment of neutrophils, monocytes, and natural killer cells in the liver to provoke inflammation [33]. Moreover, these activated immune cells and secreted inflammatory cytokines are responsible for the production of reactive oxygen/nitrogen species (ROS/RNS) [43-45] and hepatocyte death [46, 47]. Previous studies have adopted different strategies, such as treatment with antioxidants [48, 49], overexpression of anti-apoptotic Bcl-2 [50], HO-1 [51, 52], or AKT [53], and 


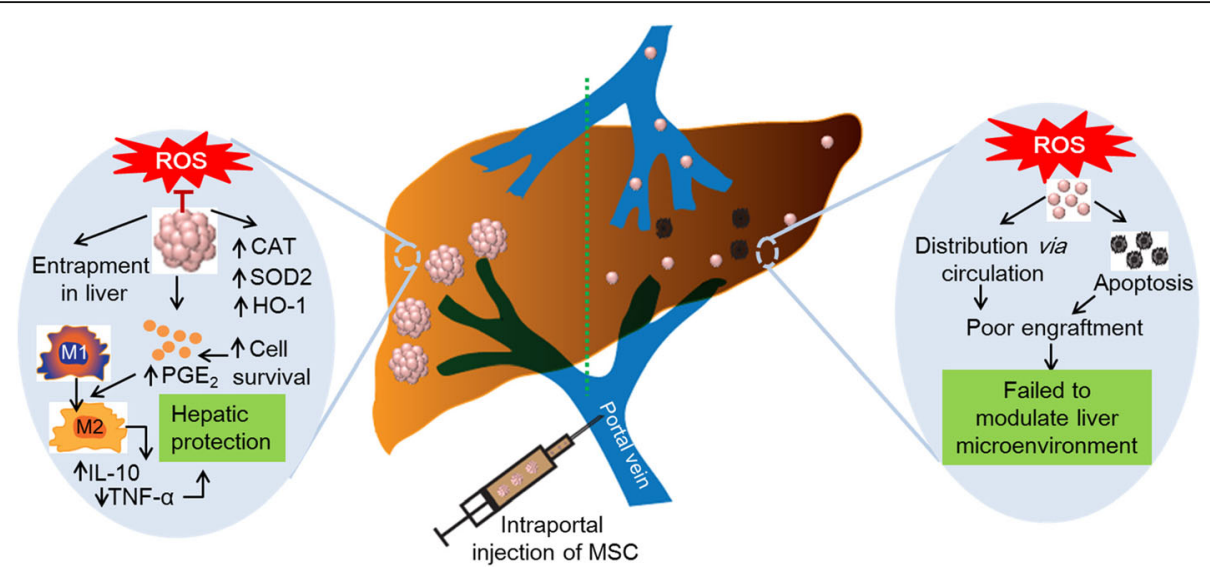

Fig. 7 Proposed mechanism of hepatoprotection by intraportally delivered MSC spheroids. Majority of the 2D-ADSC die due to oxidative stressful environment in the inflamed liver or distribute to distant organs via circulation. This leads to a poor engraftment of MSC in the liver and failure of MSC to modulate liver microenvironment. In contrast, local delivery of 3D-ADSC via portal vein results in the engraftment of 3D-ADSC into liver sinusoids. In addition, upregulation of the antioxidant defense enzymes, such as HO-1, CAT, and SOD2, enhances survival of the 3D-ADSC against the oxidative stressful environment in the liver. This leads to a secretion of higher levels of $\mathrm{PGE}_{2}$ by $3 \mathrm{D}-\mathrm{ADSC}$ which programs macrophage polarization from $\mathrm{M} 1$ to M2 phenotype. The M2 macrophages secrete higher level of IL-10 and lower level of TNF-a which results in hepatoprotection

hypoxic preconditioning [54], to improve MSC survival. In the present study, we used $3 \mathrm{D}-\mathrm{ADSC}_{1000}$ which had enhanced expression of $\mathrm{Bcl}-2$ and $\mathrm{HO}-1$ and antioxidant proteins which led the MSCs to thrive well in the oxidative stressful environment after in vivo transplantation.

MSC may actively home to tissues via leucocyte-like cell adhesion and transmigration [55]. Alternatively, they may be passively entrapped into small-diameter blood vessels [56]. We delivered 3D-ADSC ${ }_{1000}$ via the portal vein to ensure passive entrapment by liver sinusoids and portal triads. During systemic infusion, a large fraction of MSC are typically trapped in lung capillaries [57], and this retention often results in poor homing [58]. Thus, local delivery of stem cells to injured sites probably promotes MSC entrapment in damaged organs [57, 59]. Although the mechanisms responsible for MSC engraftment and homing at sites of injury are unknown, various homing and adhesion molecules, such as intracellular adhesion molecule-1 (ICAM-1), vascular cell adhesion molecule-1 (VCAM-1), P-selectin, integrins, and CXCR4, have been reported to be involved [60]. Long-term culture of 2DMSC in vitro has been reported to decrease the expressions of these adhesion and homing molecules that compromise homing and engraftment efficiencies at sites of injury [61]. In a recent study, it was reported that the upregulation of CXCR4 expression in 3D aggregates promotes the adhesion of MSC spheroids with the endothelial cells [61], which would aid the localization of transplanted 3D spheroids at the site of injury. In another study, when bone marrow-derived mononuclear cell spheroids were delivered intraportally, they were found to be entrapped in the liver, whereas spheroid-derived single cells delivered intraportally drained into the systemic circulation [42].
During inflammation, high concentrations of the pro-inflammatory cytokines, such as TNF- $\alpha$ and IFN- $\gamma$, activate MSC to secrete soluble immunomodulatory factors, such as IDO, $\mathrm{PGE}_{2}$, and $\mathrm{NO}$ [62], which results in macrophage polarization to the anti-inflammatory phenotype (M2) and $\mathrm{T}$ cell switching to the regulatory phenotype [63]. Interestingly, 3D culture results in the upregulation of various pro-inflammatory cytokines, including TNF- $\alpha$, IL- $1 \alpha$, IL$1 \beta$, and IL- 8 , which creates an early inflammatory microenvironment within the 3D spheroids that activates MSC in spheroids to produce immunoregulatory factors like TNF- $\alpha$-stimulated gene/protein 6 (TSG $\left.{ }_{6}\right)$, stanniocalcin-1 (STC-1) [19], and $\mathrm{PGE}_{2}$ [20] and leads to the attenuation of inflammation or repairment of damaged tissues [64, 65]. In the present study, we observed higher $\mathrm{COX}_{2}$ and $\mathrm{PGE}_{2}$ expressions in $3 \mathrm{D}-\mathrm{ADSC}_{1000}$ compared to 2DADSC, which resulted in more IL-10 secretion but less TNF- $\alpha$ secretion from macrophages co-cultured with 3D$\mathrm{ADSC}_{1000}$ compared to the macrophages co-cultured with 2D-ADSC. Furthermore, an increase in M2 and a decrease in M1 macrophages in the liver suggested the better immunomodulatory role of 3D-ADSC spheroids. In our previous study, $\mathrm{MSC}$ were stimulated to secrete $\mathrm{PGE}_{2}$ by pretreating with muramyl dipeptide, which upregulates $\mathrm{COX}_{2}$ expression. The results reported an enhanced immunomodulatory effect in experimental colitis [66]. Similarly, IL-1 $\beta$-primed MSC were reported to be more efficient at suppressing inflammation due to the upregulation of $\mathrm{COX}_{2}$ and $\mathrm{PGE}_{2}[67,68]$. Therefore, increased $\mathrm{COX}_{2}$ expression was correlated with increased anti-inflammatory effects. In the current study, 3D-ADSC effectively ameliorated ALF compared to 2D-ADSC, at least, in part, due to increased resistance to oxidative stress via the 
upregulation of various intracellular antioxidant mechanisms and enhanced polarization of macrophages to anti-inflammatory macrophage. Further studies should reveal the effectiveness of MSC spheroids in other inflammatory diseases.

\section{Conclusion}

Intraportal delivery of 3D-ADSC led to the MSC engraftment into the liver and enhanced therapeutic outcomes in a mouse model of FHF. These promising results were observed due to an upregulation of antioxidant defense mechanism during the formation of 3D spheroids from monolayer-cultured ADSC. This resulted in higher cell viability after intraportal transplantation. Furthermore, the enhanced immunomodulatory activity of 3D-ADSC led to the effective polarization of the macrophage from pro- to anti-inflammatory phenotype resulting in the attenuation of inflammation in GalN/LPS-induced hepatic toxicity. Recently, Chondrosphere ${ }^{\circ}$ has been approved in Europe for the treatment of cartilage defects in human. Several studies including ours have revealed the superiority of 3D MSC spheroids compared to the monolayer MSC. 3D MSC spheroids have a great potential to improve the therapeutic effectiveness of MSC-based therapy. However, further studies on optimization of technique for largescale manufacturing of clinical-grade 3D spheroids and mechanism behind the improvement of MSC effect are required for clinical translation.

\section{Additional file}

Additional file 1: Figure S1. Determination of lethal dose of GalN for the induction of FHF. The percentage survival of Balb/c nude mice after intraperitoneal injection of different doses of GalN (1000 mg/kg, 1500 $\mathrm{mg} / \mathrm{kg}, 2000 \mathrm{mg} / \mathrm{kg}$, and $3000 \mathrm{mg} / \mathrm{kg}$ ) with $20 \mu \mathrm{g} / \mathrm{kg}$ LPS. Figure S2. Serum GOT and GPT level in normal mice before induction of FHF. Figure S3. Gross observation of the liver after $7 \mathrm{~h}$ of intraportal delivery of $2 \mathrm{D}$-ADSC and $3 \mathrm{D}-\mathrm{ADSC}_{1000}$. Massive infarction was observed throughout the liver after 2D-ADSC delivery. In contrast, minimal infarction was observed in the $3 \mathrm{D}-\mathrm{ADSC}_{1000}$ delivered group (the arrows indicate the areas of the infarction). (DOCX $562 \mathrm{~kb}$ )

\section{Abbreviations}

2D-ADSC: 2D-cultured adipose-derived mesenchymal stem cells; 3DADSC: 3D spheroids of adipose-derived mesenchymal stem cells; ADSC: Adipose-derived mesenchymal stem cells; ALF: Acute liver failure; ANOVA: Analysis of variance; CAT: Catalase; CCK-8: Cell Counting Kit-8; CCL2: C-C motif chemokine ligand 2; COX 2 : Cyclooxygenase 2; CXCR4: C-X-C chemokine receptor type 4; DCFDA: 2',7'-Dichlorofluorescin diacetate; ELISA: Enzyme-linked immunosorbent assay; FHF: Fulminant hepatic failure; GalN/LPS: D-Galactosamine/lipopolysaccharide; GOT: Glutamic oxaloacetic transaminase; GPT: Glutamic pyruvic transaminase; HO-1: Hemeoxygenase-1; ICAM-1: Intercellular Adhesion Molecule 1; IDO: Indoleamine 2,3 dioxygenase; IL-1 a: Interleukin 1 alpha; IL-10: Interleukin-10; IL-1ß: Interleukin 1 beta; IL8: Interleukin 8; MSC: Mesenchymal stem cells; PCR: Polymerase chain reaction; $\mathrm{PGE}_{2}$ : Prostaglandin $\mathrm{E}_{2}$; RNS: Reactive nitrogen species; ROS: Reactive oxygen species; SIRS: Systemic inflammatory response syndrome; SOD2: Superoxide dismutase 2; STC-1: Stanniocalcin-1; TBHP: Tertbutyl hydroperoxide; TF: Tissue factor; TNF-a: Tumor necrosis factor alpha;
TSG6: Tumor necrosis factor-inducible gene 6; VCAM-1: Vascular cell adhesion protein 1

\section{Acknowledgements}

Not applicable.

\section{Authors' contributions}

SR, SP, HSK, and JJH participated in the research design. SR and SP participated in the performance of the experiment. SR, SP, TPT, and TTN participated in the data analysis. SR participated in writing the manuscript. JHS, SY, JOK, CSY, IC, KOD, PHP, JBP, BKK, DML, IJM, and YS provided technical advice during the experiment and manuscript preparation. All authors read and approved the final manuscript.

\section{Funding}

This study was supported by the Basic Science Research Program through the National Research Foundation of Korea (NRF), funded by the Korean Ministry of Science, ICT, and Future Planning (grant no. 2015R1A5A2009124 and 2018R1A5A2023879) and funded by the Ministry of Education (grant no. 2017R1D1A1B03027831); by the Korea Health Technology R \& D Project through the Korea Health Industry Development Institute (KHIDI) and the Korean Ministry of Health and Welfare (grant no. HI18C0453); and by the Creative Economy Leading Technology Development Program through the Gyeongsangbuk-Do and Gyeongbuk Science and Technology Promotion Center of Korea (SF316001A).

\section{Availability of data and materials}

Authors.

Ethics approval and consent to participate

Not applicable

Consent for publication

Not applicable.

\section{Competing interests}

The authors declare that they have no competing interests.

\section{Author details}

${ }^{1}$ College of Pharmacy, Yeungnam University, 280 Daehak-ro, Gyeongsan-si, Gyeongbuk-do 38541, Republic of Korea. ${ }^{2}$ College of Pharmacy, Yonsei University, Incheon 21983, Republic of Korea. ${ }^{3}$ College of Pharmacy, Keimyung University, Daegu 42415, Republic of Korea. ${ }^{4}$ Department of Medical Biotechnology, Yeungnam University, Gyeongsan 38541, Republic of Korea. ${ }^{5}$ Department of Physiology, College of Medicine, Yeungnam University, Daegu 42415, Republic of Korea. 'Department of Periodontics, College of Medicine, The Catholic University of Korea, Seoul 06591, Republic of Korea. ${ }^{7}$ Department of Life Science in Dentistry, School of Dentistry, Pusan National University, Yangsan 50612, Republic of Korea. ${ }^{8}$ Institute for Translational Dental Sciences, Pusan National University, Yangsan 50612, Republic of Korea. ${ }^{9}$ Biomedical Manufacturing Technology Center, Korea Institute of Industrial Technology, Gyeongbuk 38822, Republic of Korea.

${ }^{10}$ WELGENE Inc., Gyeongsan 38695, Republic of Korea.

Received: 27 January 2019 Revised: 29 April 2019

Accepted: 11 July 2019 Published online: 16 October 2019

References

1. Bernal W, Auzinger G, Dhawan A, Wendon J. Acute liver failure. Lancet. 2010;376(9736):190-201.

2. Kemelo MK, Wojnarova L, Kutinova Canova N, Farghali H. D-galactosamine/ lipopolysaccharide-induced hepatotoxicity downregulates sirtuin 1 in rat liver: role of sirtuin 1 modulation in hepatoprotection. Physiol Res. 2014; 63(5):615-23.

3. Kosai K, Matsumoto K, Funakoshi H, Nakamura T. Hepatocyte growth factor prevents endotoxin-induced lethal hepatic failure in mice. Hepatology. 1999;30(1):151-9.

4. Rolando N, Wade J, Davalos M, Wendon J, Philpott-Howard J, Williams R. The systemic inflammatory response syndrome in acute liver failure. Hepatology. 2000;32(4 Pt 1):734-9. 
5. Aberg F, Isoniemi H, Hockerstedt K. Long-term results of liver transplantation. Scand J Surg. 2011;100(1):14-21.

6. Raghuram A, Restrepo A, Safadjou S, et al. Invasive fungal infections following liver transplantation: incidence, risk factors, survival, and impact of fluconazoleresistant Candida parapsilosis (2003-2007). Liver transplant. 2012;18(9):1100-9.

7. Lee KD, Kuo TK, Whang-Peng J, et al. In vitro hepatic differentiation of human mesenchymal stem cells. Hepatology. 2004;40(6):1275-84.

8. Joseph B, Malhi H, Bhargava KK, Palestro CJ, McCuskey RS, Gupta S. Kupffer cells participate in early clearance of syngeneic hepatocytes transplanted in the rat liver. Gastroenterology. 2002;123(5):1677-85.

9. Soltys KA, Soto-Gutiérrez A, Nagaya M, et al. Barriers to the successful treatment of liver disease by hepatocyte transplantation. J Hepatol. 2010; 53(4):769-74.

10. Dhawan A. Clinical human hepatocyte transplantation: current status and challenges. Liver Transplant. 2015;21(Suppl 1):S39-44.

11. Bagno L, Hatzistergos KE, Balkan W, Hare JM. Mesenchymal stem cell-based therapy for cardiovascular disease: progress and challenges. Mol Ther. 2018; 26(7):1610-23.

12. Miranda CO, Marcelo A, Silva TP, et al. Repeated mesenchymal stromal cells treatment sustainably alleviates Machado-Joseph disease. Mol Ther. 2018; 26(9):2131-51.

13. Zheng M, Kim D-Y, Sung J-H. Ion channels and transporters in adiposederived stem cells. J Pharm Invest. 2019:49(3):287-94.

14. Zhang Z, Wang FS. Stem cell therapies for liver failure and cirrhosis. J Hepatol. 2013;59(1):183-5.

15. Kuo TK, Hung SP, Chuang CH, et al. Stem cell therapy for liver disease: parameters governing the success of using bone marrow mesenchymal stem cells. Gastroenterology. 2008;134(7):2111-21 2121.e2111-3.

16. Togel F, Weiss K, Yang Y, Hu Z, Zhang P, Westenfelder C. Vasculotropic, paracrine actions of infused mesenchymal stem cells are important to the recovery from acute kidney injury. A J Physiol Renal Physiol. 2007; 292(5):F1626-35.

17. Adamiak M, Sahoo S. Exosomes in myocardial repair: advances and challenges in the development of next-generation therapeutics. Mol Ther. 2018;26(7):1635-43.

18. Yong $S-B$, Chung JY, Song Y, Kim YH. Recent challenges and advances in genetically-engineered cell therapy. J Pharm Invest. 2018;48(2):199-208.

19. Bartosh TJ, Ylöstalo JH, Mohammadipoor A, et al. Aggregation of human mesenchymal stromal cells (MSCs) into 3D spheroids enhances their antiinflammatory properties. Proc Natl Acad Sci. 2010;107(31):13724-9.

20. Ylöstalo JH, Bartosh TJ, Coble K, Prockop DJ. Human mesenchymal stem/ stromal cells cultured as spheroids are self-activated to produce prostaglandin E2 that directs stimulated macrophages into an anti-inflammatory phenotype. Stem Cells. 2012;30(10):2283-96.

21. Zhang S, Liu P, Chen L, Wang Y, Wang Z, Zhang B. The effects of spheroid formation of adipose-derived stem cells in a microgravity bioreactor on stemness properties and therapeutic potential. Biomaterials. 2015;41:15-25.

22. Kapur $S$, Wang $X$, Shang $H$, et al. Human adipose stem cells maintain proliferative, synthetic and multipotential properties when suspension cultured as self-assembling spheroids. Biofabrication. 2012;4(2):025004.

23. Bhang SH, Cho S-W, La W-G, et al. Angiogenesis in ischemic tissue produced by spheroid grafting of human adipose-derived stromal cells. Biomaterials. 2011;32(11):2734-47.

24. Xu Y, Shi T, Xu A, Zhang L. 3D spheroid culture enhances survival and therapeutic capacities of MSCs injected into ischemic kidney. J Cell Mol Med. 2016;20(7):1203-13.

25. Fischer UM, Harting MT, Jimenez F, et al. Pulmonary passage is a major obstacle for intravenous stem cell delivery: the pulmonary first-pass effect. Stem Cells Dev. 2009;18(5):683-92.

26. Harting MT, Jimenez $F$, Xue $H$, et al. Intravenous mesenchymal stem cell therapy for traumatic brain injury. J Neurosurgery. 2009;1 10(6):1189-97.

27. Chen J, Li Y, Wang $L$, et al. Therapeutic benefit of intravenous administration of bone marrow stromal cells after cerebral ischemia in rats. Stroke. 2001;32(4):1005-11.

28. Saat TC, van den Engel S, Bijman-Lachger W, et al. Fate and effect of intravenously infused mesenchymal stem cells in a mouse model of hepatic ischemia reperfusion injury and resection. Stem Cells Intl. 2016; 2016:5761487.

29. Regmi S, Cao J, Pathak S, et al. A three-dimensional assemblage of gingiva-derived mesenchymal stem cells and NO-releasing microspheres for improved differentiation. Int J Pharm. 2017;520(1-2):163-72.
30. Pathak S, Regmi S, Nguyen $\Pi$, et al. Polymeric microsphere-facilitated site-specific delivery of quercetin prevents senescence of pancreatic islets in vivo and improves transplantation outcomes in mouse model of diabetes. Acta Biomater. 2018;201(10):24392-405.

31. Ren $X$, Zhang $Y$, Snyder J, et al. Forkhead box M1 transcription factor is required for macrophage recruitment during liver repair. Mol Cell Biol. 2010;30(22):5381-93.

32. Pathak S, Regmi S, Gupta B, et al. Engineered islet cell clusters transplanted into subcutaneous space are superior to pancreatic islets in diabetes. FASEB J. 2017;31(11):5111-21.

33. Yang $Q$, Shi $Y, H e J$, Chen $Z$. The evolving story of macrophages in acute liver failure. Immuno Lett. 2012;147(1-2):1-9.

34. Wang Y, Chen X, Cao W, Shi Y. Plasticity of mesenchymal stem cells in immunomodulation: pathological and therapeutic implications. Nat Immunol. 2014;15(11):1009-16.

35. Sato $\mathrm{Y}$, Araki $\mathrm{H}$, Kato J, et al. Human mesenchymal stem cells xenografted directly to rat liver are differentiated into human hepatocytes without fusion. Blood. 2005;106(2):756-63.

36. Luo X-Y, Meng X-J, Cao D-C, Wang W, Zhou K, Li L, Guo M, Wang P. Transplantation of bone marrow mesenchymal stromal cells attenuates liver fibrosis in mice by regulating macrophage subtypes. Stem Cell Res Ther. 2019;10(16). https://doi.org/10.1186/s13287-018-1122-8.

37. Chang W, Song BW, Moon JY, et al. Anti-death strategies against oxidative stress in grafted mesenchymal stem cells. Histol Histopathol. 2013;28(12):1529-36.

38. Mangi AA, Noiseux N, Kong D, et al. Mesenchymal stem cells modified with Akt prevent remodeling and restore performance of infarcted hearts. Nat Med. 2003;9(9):1195.

39. Baldari S, Di Rocco G, Piccoli M, Pozzobon M, Muraca M, Toietta G. Challenges and strategies for improving the regenerative effects of mesenchymal stromal cell-based therapies. Int J Mol Sci. 2017;18(10):2087.

40. Petrenko Y, Syková E, Kubinová Š. The therapeutic potential of threedimensional multipotent mesenchymal stromal cell spheroids. Stem Cell Res Ther. 2017:8:94

41. Pathak S, Regmi S, Shrestha P, Choi I, Doh K-O, Jeong J-H. Mesenchymal stem cell capping on ECM-anchored caspase inhibitor-loaded PLGA microspheres for intraperitoneal injection in DSS-induced murine colitis. Small. 2019. https://doi.org/10.1002/smll.201901269.

42. Oh BJ, Jin S-M, Hwang Y, et al. Highly angiogenic, non-thrombogenic bone marrow mononuclear cells-derived spheroids in intraportal islet transplantation. Diabetes. 2018;67:473-85.

43. Asghar MN, Emani R, Alam C, et al. In vivo imaging of reactive oxygen and nitrogen species in murine colitis. Inflamm Bowel Dis. 2014;20(8):1435-47.

44. Jaeschke $H$. Reactive oxygen and mechanisms of inflammatory liver injury: present concepts. J Gastroenterol Hepatol. 2011;26(Suppl 1):173-9.

45. Jaeschke H, Ho YS, Fisher MA, Lawson JA, Farhood A. Glutathione peroxidase-deficient mice are more susceptible to neutrophil-mediated hepatic parenchymal cell injury during endotoxemia: importance of an intracellular oxidant stress. Hepatology. 1999;29(2):443-50.

46. Wei H, Li Z, Hu S, Chen X, Cong X. Apoptosis of mesenchymal stem cells induced by hydrogen peroxide concerns both endoplasmic reticulum stress and mitochondrial death pathway through regulation of caspases, p38 and JNK. J Cell Biochem. 2010;111(4):967-78.

47. Li X, Shang B, Li Y-n, Shi Y, Shao C. IFNY and TNFa synergistically induce apoptosis of mesenchymal stem/stromal cells via the induction of nitric oxide. Stem Cell Res Ther. 2019;10(18). https://doi.org/10.1186/s13287-018-1102-z.

48. Drowley L, Okada M, Beckman S, et al. Cellular antioxidant levels influence muscle stem cell therapy. Mol Ther. 2010;18(10):1865-73.

49. Valle-Prieto A, Conget PA. Human mesenchymal stem cells efficiently manage oxidative stress. Stem Cells Dev. 2010;19(12):1885-93.

50. Li W, Ma N, Ong LL, et al. BCl-2 engineered MSCs inhibited apoptosis and improved heart function. Stem Cells. 2007;25(8):2118-27.

51. Yoon SJP, Kim SJP, Lee SMP. Overexpression of HO-1 contributes to sepsis-induced immunosuppression by modulating the Th1/Th2 balance and regulatory T-cell function. J Infect Dis. 2017;215:1608-18.

52. Tang YL, Tang Y, Zhang YC, Qian K, Shen L, Phillips MI. Improved graft mesenchymal stem cell survival in ischemic heart with a hypoxia-regulated heme oxygenase-1 vector. J Am Coll Cardiol. 2005;46(7):1339-50.

53. Gnecchi M, He H, Liang OD, et al. Paracrine action accounts for marked protection of ischemic heart by Akt-modified mesenchymal stem cells. Nat Med. 2005;11(4):367-8. 
54. Hu X, Yu SP, Fraser JL, et al. Transplantation of hypoxia-preconditioned mesenchymal stem cells improves infarcted heart function via enhanced survival of implanted cells and angiogenesis. J Thorac Cardiovasc Surg 2008;135(4):799-808

55. Khaldoyanidi S. Directing stem cell homing. Cell Stem Cell. 2008;2(3): 198-200.

56. Karp JM, Leng Teo GS. Mesenchymal stem cell homing: the devil is in the details. Cell Stem Cell. 2009;4(3):206-16.

57. Barbash IM, Chouraqui $P$, Baron J, et al. Systemic delivery of bone marrowderived mesenchymal stem cells to the infarcted myocardium: feasibility, cell migration, and body distribution. Circulation. 2003;108(7):863-8.

58. Toma C, Wagner WR, Bowry S, Schwartz A, Villanueva F. Fate of cultureexpanded mesenchymal stem cells in the microvasculature. Circ Res. 2009; 104(3):398-402.

59. Amado LC, Saliaris AP, Schuleri KH, et al. Cardiac repair with intramyocardial injection of allogeneic mesenchymal stem cells after myocardial infarction. Proc Natl Acad Sci. 2005;102(32):11474-9.

60. Docheva D, Popov C, Mutschler W, Schieker M. Human mesenchymal stem cells in contact with their environment: surface characteristics and the integrin system. J Cell Mol Med. 2007;11(1):21-38.

61. Potapova IA, Brink PR, Cohen IS, Doronin SV. Culturing of human mesenchymal stem cells as three-dimensional aggregates induces functional expression of CXCR4 that regulates adhesion to endothelial cells. J Biol Chem. 2008;283(19):13100-7.

62. Uccelli A, Moretta L, Pistoia V. Mesenchymal stem cells in health and disease. Nat Rev Immunol. 2008:8(9):726-36.

63. Bernardo ME, Fibbe WE. Mesenchymal stromal cells: sensors and switchers of inflammation. Cell Stem Cell. 2013;13(4):392-402.

64. González MA, Gonzalez-Rey E, Rico L, Büscher D, Delgado M. Adipose-derived mesenchymal stem cells alleviate experimental colitis by inhibiting inflammatory and autoimmune responses. Gastroenterology. 2009;136(3):978-89.

65. Shi Y, Su J, Roberts Al, Shou P, Rabson AB, Ren G. How mesenchymal stem cells interact with tissue immune responses. Trends Immunol. 2012;33(3):136-43.

66. Kim HS, Shin $\mathrm{TH}$, Lee BC, et al. Human umbilical cord blood mesenchymal stem cells reduce colitis in mice by activating NOD2 signaling to COX2. Gastroenterology. 2013;145(6):1392-403 e1391-8.

67. Fan $H$, Zhao G, Liu L, et al. Pre-treatment with IL-1beta enhances the efficacy of MSC transplantation in DSS-induced colitis. Cell Mol Immunol. 2012;9(6):473-81.

68. Regmi S, Pathak S, Kim JO, Yong CS, Jeong J-H. Mesenchymal stem cell therapy for the treatment of inflammatory diseases: challenges, opportunities, and future perspectives. Eur J Cell Biol. 2019. https://doi.org/1 0.1016/j.ejcb.2019.04.002

\section{Publisher's Note}

Springer Nature remains neutral with regard to jurisdictional claims in published maps and institutional affiliations.

Ready to submit your research? Choose BMC and benefit from:

- fast, convenient online submission

- thorough peer review by experienced researchers in your field

- rapid publication on acceptance

- support for research data, including large and complex data types

- gold Open Access which fosters wider collaboration and increased citations

- maximum visibility for your research: over $100 \mathrm{M}$ website views per year

At $\mathrm{BMC}$, research is always in progress.

Learn more biomedcentral.com/submissions 